\title{
THE ROLE OF TRANS-NATIONAL NETWORKS IN TECHNOLOGY TRANSFER AND INNOVATION
}

\author{
Daniela Sani \\ Kussai Shahin \\ ASTER S.Con.p.A., Bologna, Italy
}

\begin{abstract}
Technology transfer and innovation is one of the main challenge of the European Community to "drive innovation and competitiveness by connecting knowledge, technologies and people". In this field, the paper aims to present the results of technology transfer actions at trans-national level obtained by NETTI - Network in the Energy Field: Technology Transfer (TT) and Innovation, thanks also to effective cross cooperation with other TT networks highlighting the importance of synergies and combining resources and initiatives. The lesson learned shows the opportunities and the results that could be obtained by an efficient collaboration between interregional and trans-national actions.
\end{abstract}

\section{KEYWORDS}

Technology transfer; Innovation; Network; Knowledge transfer.

\section{INTRODUCTION}

Technology transfer (TT) is the process of developing practical applications for the results of scientific research [1]. De Bandt in [2] considers that is an ambiguous term, because it suggests wrongly that technology is a well defined finished product which can thus be transferred and used as such. In fact, it is a not an easy process because it involve a series of scientific, technological, organisational, financial and commercial activities [3].

If from one hand the identification of TT opportunities is complex, on the other hand "valuation of technology transfer opportunity" is one of the trickiest and most critical challenges to face. Technology transfer promoter are often caught in the middle of a frustrating tug-of-war, between inventors who want the moon for their innovation and potential licensees who want to "low-ball to death" [4]. Networking could represent for TT promoter a useful instrument because it should be held by anyone who has an important role in discovering, encouraging, funding or promulgating the transfer or translation of research into useful, practical products which can yield wide benefits.

The present paper aims to analyze the role of networks in enhancing technology transfer and innovation by comparing the activities and results of regional and trans-national networks and their cross cooperation. In particular, the analyses are focused on the networks operating within the Emilia-Romagna region (Italy) fostering innovation within the territory and beyond. The methodology is based on a comparison between the networks performance and their correlations ensured by the presence of ASTER, the regional consortium for industrial research, technology transfer and innovation gathering together with the different regional 
innovation actors and acting also as a gateway between the regional level and the European one promoting and exploiting trans-national cooperation opportunities.

\section{THE TECHNOLOGY TRANSFER NETWORKS}

In Emilia-Romagna region three Technology Transfer and Innovation networks are operating within the regional territory and beyond:

- Emilia-Romagna High-Tech Network [5]

- IRC-IRENE Innovation Relay Centres Network [6]

- NETTI: Networks in the Energy field: Technology Transfer and Innovation [7]

These networks, supported by the Regional Government, lead to the same direction even they have different concepts and philosophy. In fact, all of them aims to foster and to reinforce the competitiveness of the territory in line with the European idea of "think globally, act locally" [8]. The Emilia-Romagna High-Tech Network is composed by structures dedicated to industrial research, technology transfer and innovation across the whole region and coordinated by ASTER. It was born following the strategic approach of the regional industrial policy for the improvement of the competitiveness based on the knowledge economy.

IRC-IRENE is a centre of the European Innovation Relay Centres Network (IRC) that supports innovation and trans-national technological co-operation in Europe with a range of specialised business support services [6,9]. The IRC-IRENE activities are managed and hosted, within the Emilia-Romagna region, by ASTER that collaborates with the other 71 regional IRCs spanned over 33 countries - 27 EU Member States, Iceland, Israel, Norway, Switzerland, Turkey and Chile forming a wide horizontal network.

Lastly, NETTI, a project co-funded by the Regional Framework Operation (RFO) Programme under the INTERREG IIIC initiative enercy'regio, can be considered an example of a vertical trans-national network. In fact, NETTI "Network in the Energy Field: Technology Transfer and Innovation" operates into a small partnership of 5 European regions fostering technology transfer and innovation in the energy sector, where ASTER has had the role of project coordinator.

\subsection{Emilia-Romagna high-tech network}

Emilia-Romagna region is strengthening its position as knowledge based economy: both private and public actors strongly believe in the increased strategic importance of Research and Development $(R \& D)$ and Innovation for the competitiveness of the regional industry. For this reason Emilia-Romagna has endorsed a regional policy for R\&D and innovation focused on the promotion of industrial research, technological development and the transfer of new technologies from knowledge production centres to the regional industrial system.

The regional policy for research and innovation aims at the promotion of closer interactions between businesses, research institutes, the university and the centres for technology transfer operating in the region, and is based on the Law for Innovation (Law n.7, issued in 2002, [10]) and on its implementing programme, the so called PRRIITT (Programma Regionale per la Ricerca Industriale, l'Innovazione e il Trasferimento Tecnologico), namely Regional Programme for Industrial Research, Innovation and Technology Transfer, started in 2003.

Thanks to the PRRIITT Programme and to further regional resources (in particular ERDF Ob. 2 funds), the Emilia-Romagna High-Tech Network eventually set up in 2005. The Network counts 57 structures dedicated to industrial research, technology transfer and innovation 
across the whole region. It involves over 1,300 companies and employs 1,500 new research personnel. As for the financial dimension, the overall public regional investment amounts at 156.6 Million Euro (for a two year period), as co-financing of a total investment of 367.5 Million Euro.

One of the main strength is that the network [5] is widespread over the region (see Figure 1), connecting facilities and highly qualified human resources. The Network comprises 27 Industrial Research Laboratories, 24 Innovation Centres and 6 Innovation Parks operating in seven key sectors:

- Advanced Mechanics (HI-MECH District);

- Environment, Sustainable Development and Energy;

- Agro-Food Industry;

- Building and Construction;

- Life Sciences and Health;

- Organisational Innovation;

- Information and Communication Technologies (ICT).

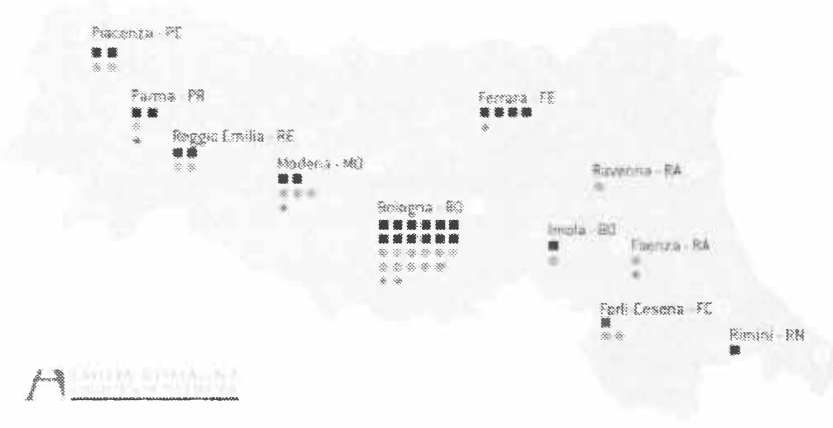

Figure 1. Schematic territorial distribution of Emilia-Romagna High-Tech network.

Referring in particular to Environment Energy and Sustainable Development, the network counts 5 Laboratories and 1 Centre:

- LEAP: Efficiency and Environmental Compatibilities of Energy Technologies

- ERG: Networked Laboratory for Research and Technology Transfer in the Energy Sector

- LARA: Regional Network Water Laboratories

- LaRIA: Regional Laboratory for Innovation in Air Quality Control

- LITCAR: Integrated Technologies and Environmental Control Laboratory in the Waste Life Cycle

- CISA: Centre for Innovation and Environmental Technologies for Sustainability of the Apennine

The concept behind Laboratories, Centres and Parks is to gather around a common project all the different research resources working on a same thematic issues and the enterprises interested in the potential outcomes of research in such field, with the aim of coordinating efforts, optimising results and valorising them at best and timely within the productive system 
fostering its competitiveness. Laboratories and Centres are real regional thematic research clusters of excellence. The thematic areas over which they operates respond to the research priorities of the local productive system and converge with the research platforms identified ad strategic at the European level.

The network is supported by ASTER, the consortium for industrial research, technology transfer and innovation created among the Emilia-Romagna Regional Government, the Universities of the region, important national Research Centres such as CNR, ENEA, INAF and INFM, the regional Union of Chambers of Commerce and Industry and the regional Entrepreneurial Associations. The consortium operates at the very core of the Network, by gathering together the different actors involved: it acts as trait d'union facilitating research and industry relations. In particular, it ensure the links between the Emilia-Romagna HighTech network and the trans-national ones promoting interaction across Europe, creating reciprocal awareness and fostering collaboration among the network nodes and potential European partners. For instance, it is worth to underline the successful initiative "Research to Business" (R2B) fair [11], an international event held yearly in Bologna (Italy).

\subsection{IRC-IRENE innovation relay centres network}

IRC-IRENE is the Italian Relay Centre North-East [6] covering five regions in the north-east of Italy - Trentino, Friuli Venezia-Giulia, Veneto, Emilia-Romagna and Marche. According to the IRC Network mission, IRC-IRENE offers local enterprises and research centres services such as company consultancy on technological issues, technology audits, organization of technological workshops, seminars and brokerage events, partner search and support on negotiation in the process of concluding trans-national technology transfer agreements [12].

The Trans-national transfers of technology - signed agreements for the sale, licensing, distribution or joint development of new technologies - are based on technology offer and/or request $(\mathrm{TO} / \mathrm{TR})$ of the enterprises, research institutes, universities, technology centres and innovation agencies.

ASTER is the IRC-IRENE reference partner for the Emilia-Romagna region, providing the IRC services towards the actors of its territory. It has developed a set of customized practices to enhance the effectiveness of the standard package of services provided by the IRC network raising awareness of IRC services added value among the local community.

For instance, an important methodology tested over the last years consists in a particularly efficient way for spreading the TOs and TRs coming from foreign IRCs among the local business and scientific communities. This methodology consists in selecting technology profiles, on the basis of the regional interests and the seven key areas of he Emilia-Romagna High-Tech Network. These profiles are then published on the weekly magazine issued by the main national financial newspaper and specifically dedicated to the central and northern Italian business community, "Sole 24 Ore - Inserto Centro Nord". The service has the double value added of been free of charge and constantly guaranteed, while the trustworthiness of the newspaper itself guarantees the reliability of IRC postings in the perception of end-users. The methodology, proposed and tested by ASTER since 2001, has been adopted by other IRCs partners and was acknowledged as a best practice at the level of the entire European IRC Network. Due to the successful results of this practice, ASTER further strengthened the regional dissemination of TOs and TRs integrating it in its on-line information service, F1RST [13], which records approximately 7500 registered users among businessmen and 
researchers. F1RST users are mostly based in Emilia-Romagna, but the newsletter reaches a large number of clients all around Italy further raising awareness on the IRC Network at the national level and fostering collaboration of the other Italian IRCs with their territories.

\subsection{NETTI: Networks in the Energy field: Technology Transfer and Innovation}

NETTI - Networks in the Energy field: Technology Transfer and Innovation - is a project cofunded by the Regional Framework Operation (RFO) Programme under the INTERREG IIIC initiative enercy'regio [14]. It includes five European regions, namely: Saxony (Germany), Smaland Med Öarna (Sweden), Emilia-Romagna (Italy), Crete (Greece) and Border Midland and Western (Ireland).

NETTI aims at promoting inter-regional cooperation in order to facilitate the creation (or enhancement) of thematic networks in energy-specific fields that involve all interested key actors and support the development and planning of specific projects. Led by ASTER, the project benefits from the synergies emerging from inter-regional cooperation that will allow identification of the most suitable tools to promote technology transfer within the energy sector.

The NETTI partnership involves experienced partners from the above mentioned regions, namely: ASTER S. Cons. p.a., Nomisma S.p.A and Confederazione Italiana Agricoltori for the Emilia-Romagna. Bautzen Innovation Centre, Riesa-Großenhain Innovation Centre and Business Innovation Centre Zwickau GmbH for Saxony. Kalmar Regional Council for Smaland and Öarma, Technical University of Crete for Crete and Energy Crops Ltd for Border, Midland and Western.

The adopted methodology can be schematised in 3 main phases. The definition (including regional potential identification and assessment) and the animation (including creation and inter-regional exchanges) of the network constitute the preparatory stages of the network approach. Test pilots complete and become effective the strategy of the project network. In figure 3 the NETTI's approach methodology.

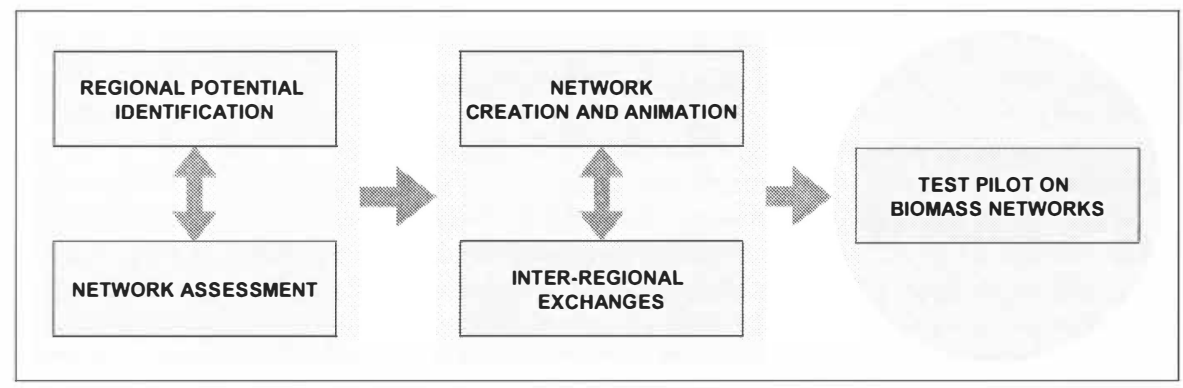

Figure 2. NETTI network approach methodology.

The assessment of current innovation potential in each participant region is undertaken to develop the basis for a vertical network in the energy field. The analysis of technology supply and demand helps in identifying opportunities for technology transfer involving two main elements: the competences of research centres and universities and the technology transfer potential of industry. The results of the assessment can be viewed on-line in the NETTI 
website, incorporating a data base of all participating companies and research institutions. NETTI partners have free access to the project data base, which is continually updated, thus enhancing the building of the network throughout Europe.

One of NETTI key functions is to implement specific network activities focusing on the more promising technologies and processes that were identified according to the key energy priorities of the regions involved. Particularly promising areas for cooperation are: solar photovolatic systems and research; biomass energy systems based on different feedstocks; fuel cells, their components and applications; multi-utilities' renewable energy sources requirement expands market for renewable energy technologies and services, new design wind energy systems with lower environmental impact.

Animation of the network is consisting of: interregional exchanges, pilot projects, brokerage event participation, organisation of bilateral meetings and seminars, information dissemination and communication activities. Interregional exchanges take place according to a visiting scheme. This tool is particularly useful and effective in the transfer of knowledge and good practices between partners as well as the facilitation of trans-national transfers of technology. Five study visits, one in each country, were planned, organised and implemented. Most of the promising priorities in the energy field were covered in the study visit programme to favourite the sharing of experiences and good practices.

Specific pilot exercises focused on biomass are being implemented in two local networks operating in Emilia Romagna and Border, Midland and Western regions: the Farini - Val Nure and the Donegal pilot networks. Based in Donegal, Energy Crop Ltd. has been supported by NETTI to develop local businesses around indigenous biomass resources. The network aims to commercialise the production and utilisation of agricultural biomass by planting and maintaining dedicated crops such as short rotation coppice. The Italian Farmers' Confederation has joined NETTI with the objective of developing local business using indigenous biomass resources from the Val Nure, including Appennine Mountain and valley. The exploitation of local forestry resources for energy is made possible though the production of chips from residual wood collected in the Val Nure forest, after the theoretical evaluation of the real energetic capability. Local agro-forest entrepreneurs joint an integrated network in order to supply wood chips to the Farini municipality and exploit opportunity of be directly involved in the energy business as Energy Service Company.

\section{NETWORK OF NETWORKS: COMBINING RESOURCES}

Thanks to its mission and its involvement in the different networks ASTER has ensuring synergies and cross cooperation between them and combining resources. Having a wide vision of the different opportunities and complementarities, ASTER has individuating the most appropriate ways to create effective links and collaborations between the regional and the trans-national networks (see Figure 3).

It is continuously analysing and proposing methodologies and instruments in order to improve the knowledge and technology transfer. The networking and the exchange of experiences and practices are the key for the identification of effective initiatives able to strengthen innovation culture, reciprocal awareness and collaboration among people. It considers all the established networks as a fundamental tool for speeding up innovation and partnership, operating a consistent and effective animation by means of interregional exchanges, pilot projects, 
brokerage event, technology transfer fair, bilateral meetings and seminars, information dissemination and communication activities.

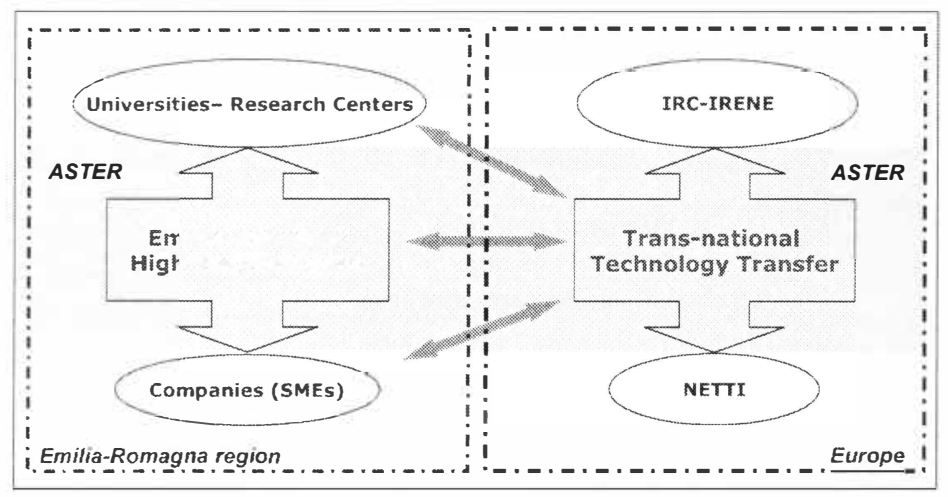

Figure 3. Schematic example of network synergies.

Within this context, the opportunities offered by the three above described network has been gathered. For instance, the Emilia-Romagna High-Tech, IRC-IRENE and NETTI have joined their efforts and activities in different occasions obtaining relevant benefits for the respective actors. For instance, they have participated to two brokerage events organised the European IRC Network, namely: ECO-Matchmaking - Building Technology Partnerships for Sustainable Business in Eco-Tech Scandinavia 2006 and Innovat\&Match in Research to Business (R2B) 2007.

\section{RESULTS AND LESSON LEARNED}

Promoting trans-national technology transfer (TTT) is one of the European Commission's main priorities as it seeks to foster innovation [15, 16]. Since the IRC network was first launched, TTT activities have been evolving constantly, taking different forms and involving increasing numbers of local operators. The Commission is keen to continue stimulating innovation in Europe by testing new approaches and identifying new methods of promoting and encouraging TTT processes [17]. Under this light, the IRC-IRENE experience have pointed out that synergies operated with other regional and trans-national networks during events gave the opportunity to maximise the effort improving the way in fostering and supporting the TTT processes. In fact, in occasion of R2B "Research to Business" IRCIRENE organised the Innovat\&Match 2007 involving the Emilia-Romagna High-Tech and NETTI networks obtaining interesting results. An example of output indicators are pointed out in Table 1 . 
Table 1. Innovat\&Match 2007 output indicators.

\begin{tabular}{|c|c|}
\hline Participants & 100 \\
\hline Organizations & 92 \\
\hline Countries & 11 \\
\hline Published profiles & 123 \\
\hline Bilateral meetings & 99 \\
\hline Trans-national Bilateral meetings & 75 \\
\hline
\end{tabular}

Regarding the specific energy sector, the assessment of current innovation potential in each participant region was undertaken in NETTI project to develop the basis for a vertical network in the energy field. Involving more than 250 actors coming from research institution and SMEs. Both identification and establish long term cooperation/agreement requested long time. Although only 15 months of activities, good social contact and interests in energy field are two positive outcomes form NETTI project. Some indicators are listed in Table 2. Referring to the new project/activities obtained by NETTI, it is worth to point out: 4 formalized networks in biomass and a fuel cell; 2 TTT agreements concretized in occasion of Innovat\&Match 2007 thanks to the IRC-IRENE tutoring and synergies.

Table 2. NETTI output indicators.

\begin{tabular}{|c|c|}
\hline Research institutions assessed & 56 \\
\hline Public authorities assessed & 28 \\
\hline SMEs enterprises involved & 187 \\
\hline Animation network events organized or attended & 73 \\
\hline New projects/activities tutored & 11 \\
\hline
\end{tabular}

Because of the young constitution of the Emilia-Romagna High-Tech network, indicators of performances are not easy to present. An example of the aggregated data is showed in Table 3. To be put in evidence is the relevant number of young researches involved in the network, satisfying completely the Lisbon Strategy [18]. Another aspect to measure the network performances is the capacity of the laboratories to reach project-financing and become independent from public support. In two years, 2 of the 6 constituted Laboratories are established a stable consortium structure.

Thanks to the synergies and networking between NETTI and the Emilia-Romagna High-Tech networks, several trans-national collaborations has been started. For example, actors of the two networks individuated technological cooperation opportunities that also lead to prepare and submit several European project proposals. 
Table 3. Environment Energy and Sustainable Development high-tech network indicators.

\begin{tabular}{|c|c|}
\hline Consortium established & 2 \\
\hline Agreements & 43 \\
\hline Patents & 5 \\
\hline Young researchers & 89 \\
\hline Research centers & 36 \\
\hline SME s and private investors & 34 \\
\hline Public bodies & 8 \\
\hline
\end{tabular}

\section{CONCLUSIONS}

Technology Transfer could be achieved in an effective way combining the interregional contexts, especially considering the fact that the European Community constitutes a great opportunity in this sense.

The identification of synergies between existing networks and initiatives is crucial to improve their overall effectiveness and impacts. This is particularly true, as highlighted by the present paper for a complex process like the innovation one.

The coexistence of horizontal and vertical networks should be seen as an added value for the complementarities of their services and approaches. Finally, the role of a regional actor, well connected to the regional innovation policy, is fundamental in order to speed-up a systemic change sharing objectives and tools, overcoming fragmentation and expediting commitment and interaction.

\section{ACKNOWLEDGEMENT}

The authors wish to thanks all NETTI partners for their excellent collaboration and friendship during project operation, as well as the overall enercy'regio Steering Committee. They want also to thanks University of Kalmar and Kalmar Regional Council for the opportunity to attend the Second Baltic Symposium on Environmental Chemistry.

\section{REFERENCES}

[3] Web source of $8^{\text {th }}$ October 2007: http://en.wikipedia.org/wiki/Technology_transfer

[4] De Bandt, J. 1999. Knowledge and technology transfer. Proc. NATO Advanced Research Workshop, Budapest, 1998, Ed. Springer, 23-35.

[5] European Commission, 2005. Oslo Manual: Guidelines for Collecting and Interpreting Innovation Data, $3^{\text {rd }}$ Ed. OECD Publishing, ISBN 9789264013087

[6] Web source of $8^{\text {th }}$ October 2007: http://www.technologytransfertactics.com

[7] Web source of $8^{\text {th }}$ October 2007: http://www.aster.it/index.php?newlang=eng

[8] W'eb source of $8^{\text {th }}$ October 2007: http://www.irc-irene.org

[9] Web source of $8^{\text {th }}$ October 2007: http://www.aster.it/netti.html

[10] Web source of $8^{\text {th }}$ October 2007: http://en.wikipedia.org/wiki/Frank_Feather

[11] Web source of $26^{\text {th }}$ September 2007: http://irc.cordis.lu/home.cfm 
[12] Regional Law n.7 of the $14^{\text {th }}$ May 2002. Promozione del sistema regionale delle attività di ricerca industriale, innovazione e trasferimento tecnologico. BUR 64/14 maggio 2002 (internet source of $26^{\text {th }}$ September 2007: http://burer.regione.emiliaromagna.it/BUR/servlet/AdapterHTTP?PAGE=TELEMATICO_INDEX_PAGE\&ANN $\mathrm{O}=2002 \&$ NUMBOLL $=64$ ).

[13] Web source of $8^{\text {th }}$ October $2007:$ http://www.rtob.it/index.asp? $\mathrm{m}=79 \& \mathrm{l}=2 \& \mathrm{ma}=144$

[14] Gessner, W. 2006. IRC network must adapt to globalisation. European Innovation, 2, 18

[15] Web source of $8^{\text {th }}$ October 2007: http://first.aster.it

[16] Web source of $8^{\text {th }}$ October 2007: http://www.enercyregio.net

[17] European Communities (EC) Commission Directorate - General Enterprise and Industry, 2007. European competitiveness report 2006. Publications office. ISBN 9279025783

[18] European Commission and Eurostat, 2007. Science, technology and innovation in Europe, Publications office. ISBN 978-92-79-04968-2

[19] European Commission, 2007. Improving support for transnational technology transfer. Publications office. ISBN 92-79-03710-2

[20] European Commission, 2007. Implementing the renewed Lisbon strategy for growth and jobs. Publications office. ISBN 92-79-03710-2. 